\title{
Microbial flora of the lower genital tract during pregnancy: relationship to morbidity
}

\author{
J. de LOUVOIS, ROSAlinde HURLEY, AND VALERIE C. STANLEY
}

From Queen Charlotte's Hospital for Women and the Institute of Obstetrics and Gynaecology, University of London, Goldhawk Road, London W6 OXG

SYNOPSIS Nineteen genera and groups of micro-organisms were isolated from the lower genital tract of $\mathbf{2 8 0}$ women at their first antenatal visit. Chlamydia, viruses, and T-strain mycoplasmas were not sought, and only routine methods of anaerobic culture were used. Growth was recorded as scanty, moderate or heavy. The population studied was grouped according to age, parity, gestational stage at booking, presence and degree of severity of lower genital tract morbidity, past history of vulvovaginitis, and suspicion of lower genital tract morbidity as evidenced by a request for a report on the microbiological findings. The frequency of isolation of the various microbes in health and in disease is given.

The grading of Gram-stained smears bore no relation to the isolation rates of lactobacilli, but there was a significant increase $(\mathrm{P}<0.001)$ in the isolation rates of each of the following: $M y c o-$ plasma hominis, Bacteroides spp., Trichomonas vaginalis, Gram-variable cocco-bacilli, and anaerobic streptococci in those patients with smears in which lactobacilli were adjudged to be absent.

The isolation of faecal streptococci was increased $(\mathrm{P}<0.001)$ in women aged more than 34 years. Escherichia coli $(\mathrm{P}<0.05)$ and anaerobic and microaerophilic streptococci $(\mathrm{P}<0.02)$ were isolated more frequently from those booking after the 25 th week of pregnancy. The incidence of $M$. hominis $(P<0.02)$ and of anaerobic streptococci $(P<0.05)$ increased between the first and third trimesters.

No significant positive correlations were established between the isolation rates of the various microbes and objective assessment of lower genital tract morbidity or the demonstration of pus cells, but lactobacilli were isolated less frequently $(P<0.01)$ from those with morbidity. The isolation of Candida albicans $(\mathrm{P}<0.02), T$. vaginalis $(\mathrm{P}<0.05)$, and $M$. hominis $(\mathrm{P}<0.05)$ was increased in patients in whom vulvovaginitis was suspected, and that of $T$. vaginalis $(\mathrm{P}<0.05)$ was increased in those with a past history of vulvovaginitis.

The study indicates that, other than the pathogens $T$. vaginalis and $C$. albicans, only M. hominis could be suspected, on statistical grounds, of being associated with disease of the lower genital tract during early pregnancy.

Although many papers deal with the isolation of particular pathogens, or potential pathogens, from the vagina, there have been few attempts at more comprehensive studies (Edmunds, 1959; Slotnick et al, 1963 and 1964; Gordon et al 1966). The literature is briefly reviewed by Hurley et al (1974), who discuss the factors that may influence the microflora and comment on the difficulty of attempting clinicopathological correlations. The present investigation was designed to investigate the ecology of the lower

Received for publication 25 March 1975. genital tract during pregnancy and to seek relationships that may exist between signs or symptoms of morbidity and the isolation of particular microbes, as a basis for further study. Viruses, Chlamydia, and T-strain mycoplasmas were not sought.

The microbiological studies were made on 280 pregnant women, of whom $80 \%$ were Caucasian, $89 \%$ were married, and $89 \%$ were aged between 18 and 34 years. All were examined by speculum at the booking visit. Observations on lower genital tract morbidity were recorded and analysed. In addition to the whole population, groups within it were 
selected for correlative analysis with the microbiological findings on the basis of age, parity, gestational stage at booking, past history of vulvovaginitis, clinical suspicion of vulvovaginitis, and presence and degree of severity of lower genital tract morbidity. The clinical findings and criteria of grouping are reported elsewhere (Stanley et al, 1975).

\section{Material and Methods}

\section{LABORATORY INVESTIGATIONS AND METHODS}

Eight specimens were collected from each patient. Swabs were taken from: (1) the posterior fornix, during speculum examination, using a sterile foam plastic sponge $(3 \times 1 \times 1 \mathrm{~cm})$ held in sterile forceps (Hurley et al, 1974, fig 1) and a dry cotton wool swab; (2) the rectum, urethra, and cervix, using charcoal swabs (Exogen); (3) the cervix, by circumferential sweep round the margin of the external os using an Ayre's spatulum. A midstream specimen of urine was also obtained, and blood was taken for serological tests and haemoglobin estimation. The sponge swab was placed in $2 \mathrm{ml}$ of Stuart's transport medium. The charcoal swabs from rectum, urethra, and cervix were plated in the clinic onto warm gonococcal selective agar (Oxoid), and those from the urethra and cervix were plated also onto warm $10 \%$ heated blood agar.

In the laboratory, smears were prepared from the dry cotton wool swab of the posterior fornix for examination and grading by Gram-staining (Gordon et $a l, 1966)$ and from the cervical sweep for staining by Papanicolau's method. The midstream specimens of urine were screened for significant bacteriuria using a $1 \mu \mathrm{l}$ plastic disposable loop (Joblin) to inoculate CLED agar (Oxoid) for colony counting. Those yielding a count of more than 100000 organisms per ml were fully examined by routine methods. The screening tests for syphilis used in the hospital are those described by Hare (1973).

The sponge swab was squeezed out into the Stuart's medium and then discarded. The transport medium was well mixed and used to prepare wet films which were examined for Trichomonas vaginalis, and to inoculate all primary media other than those mentioned above. A standard inoculum of $0.05 \mathrm{ml}$ was spread onto 11 basic media-horse blood agar, heated horse blood agar, crystal violet horse blood agar, tellurite blood agar, nalidixic acid blood agar, MacConkey agar, Rogosa agar, Sabouraud's agar, mycoplasma agar, Thayer and Martin's medium, and Trichomonas medium. Details of the constitution of the media, of the length and atmospheres of incubation, of examination of plates, of methods used in the further identification of microbes, and of the taxonomical criteria for identification used in our laboratory are given elsewhere (de Louvois et al, 1975; Hurley et al, 1974). Bacterial growth was recorded as scanty, moderate or heavy.

\section{Results}

Nineteen groups, or genera, of microbes were isolated. Clostridium welchii, Neisseria gonorrhoeae, Listeria monocytogenes, Haemophilus species, and Lancefield group A streptococci, although sought, were not found. Microbes which were isolated from less than $1.5 \%$ of the population, viz., Neisseria spp. (N. pharyngis and N. catarrhalis) $1.4 \%$, Klebsiella aerogenes $0.7 \%$, Pseudomonas aeruginosa $0.4 \%$, and genera, or species, of yeasts, other than Candida albicans or Torulopsis glabrata (collectively $2.8 \%$ ), are excluded from further comment in this report. However, it is worth noting that one of the yeast isolates was of an unpublished new species of Pichia (Leask and Yarrow, 1974).

Seventy-three percent of smears showed a grade I film on Gram-staining, the flora consisting wholly or predominantly of organisms morphologically resembling lactobacilli; $13 \%$ showed grade II (mixed) film; and $14 \%$ showed grade III film, lactobacilli being adjudged to be absent. The grading of Grans films bore little relation to the isolation of lactobacill since $68 \%$ of those with grade III film yieldes lactobacilli on culture, compared with $86 \%$ of those with grade I film. However, comparison between the overall cultural results of patients with grade I and grade III films showed a highly significant increase in incidence $(P<0.001)$ from patients with grade III films for each of the following: Mycoplasma hominis, Bacteroides spp., $T$. vaginalis, Gram-variable coccobacilli, and anaerobic streptococci. There was no change in the incidence of $C$. albicans. No correlation could be demonstrated between the grading of films by Gram-staining, and age, parity, gestational stage at booking, urinary tract infection, excess leucocytes in the smear, or past history of vulvovaginitis; nor did the grading relate to requests for a clinical report.

Many patients harboured Corynebacteria, micrococci, Staphylococcus epidermidis, faecal streptococci, and Escherichia coli in scanty numbers, but the other microbes were represented invariably as moderate to heavy growths. For most microbes, the lightness or heaviness of growth did not affect statistical calculations. Cultures from four patients, none of whom was on antimicrobial drugs, were sterile, while those from a further 30 patients yielded a pure growth of lactobacilli. Streptococci of Lancefield group D were included among the faecal streptococci. Of $\beta$ haemolytic streptococci, other than group $D$, 


\begin{tabular}{llll}
\hline & $\begin{array}{l}\text { Total } \\
\text { Incidence }\end{array}$ & $\begin{array}{l}\text { Healthy } \\
\text { Lower } \\
\text { Genital } \\
\text { Tract }\end{array}$ & $\begin{array}{l}\text { Morbid } \\
\text { Lower } \\
\text { Genital } \\
\text { Tract }\end{array}$ \\
\hline Number of patients & & $83(30)$ & $197(70)$ \\
Corynebacteria & 280 & $68(82)$ & $166(83)$ \\
Lactobacilli & $229(82)$ & $60(72)$ & $169(85)$ \\
Staphylococcus epidermidis & $185(66)$ & $58(70)$ & $127(64)$ \\
Micrococci & $103(37)$ & $29(35)$ & $74(37)$ \\
Faecal streptococci & $96(34)$ & $23(28)$ & $73(37)$ \\
Non-haemolytic streptococci & $12(4)$ & $4(5)$ & $8(4)$ \\
Proteus sp. & $17(6)$ & $5(6)$ & $12(6)$ \\
Escherichia coli & $54(19)$ & $11(13)$ & $43(22)$ \\
Mycoplasma hominis & $31(11)$ & $9(11)$ & $22(11)$ \\
Staphylococcus aureus & $13(5)$ & $3(4)$ & $10(5)$ \\
Bacteroides & $15(5)$ & $4(5)$ & $11(6)$ \\
Anaerobic and microaero- & & & \\
philic streptococci & $61(22)$ & $17(20)$ & $44(22)$ \\
Gram-variable cocco-bacilli & $19(7)$ & $6(7)$ & $13(7)$ \\
B-haemolytic streptococci & $25(9)$ & $9(11)$ & $16(8)$ \\
Trichomonas vaginalis & $7(3)$ & $1(1)$ & $6(3)$ \\
Torulopsis glabrata & $11(4)$ & $3(4)$ & $8(4)$ \\
Candida albicans & $47(17)$ & $14(17)$ & $33(17)$ \\
\hline
\end{tabular}

Table I Relationship between lower genital tract morbidity and the isolation rate for selected microorganisms

${ }^{1}$ Includes two mixtures of yeasts.

Percentages given in parentheses.

15 belonged to Lancefield group B and eight isolates were untypable.

Dividing the population into those with no signs or symptoms of lower genital tract morbidity $(30 \%)$, those with minimal morbidity (39\%), and those with gross morbidity $(32 \%)$ showed that there were no significant differences in the rates of isolation of microbes in these groups. However, on contrasting healthy patients with those showing any degree of morbidity, no matter how slight, there was a decrease in the frequency of isolation of lactobacilli $(P<0.01)$ in those with morbidity (table I). No other differences were observed.

The microbial flora of three groups of obstetric high-risk patients is shown in table II. The isolation of faecal streptococci was increased $(P<0.001)$ in women aged more than 34 years; and that of $E$. coli $(P<0.05)$ and of anaerobic and microaerophilic streptococci $(P<0.02)$ was increased in women booking after the 25 th week of gestation. If scanty growth of these microbes was disregarded, the differences in isolation rates were not significant. The microbial flora of patients booking during the third trimester differed from that of patients booking in the first trimester in that there was a higher incidence of $M$. hominis $(\mathrm{P}<0.02)$ and of anaerobic streptococci $(P<0.05)$ in the former group.

Table III shows the distribution of micro-organisms from patients for whom a laboratory report was requested or who had a past history of vulvo-

\begin{tabular}{lllll}
\hline & $\begin{array}{l}\text { Total } \\
\text { Inci- } \\
\text { dence }\end{array}$ & $\begin{array}{l}\text { Age } \\
>34 \text { yr }\end{array}$ & $\begin{array}{l}\text { Parity } \\
>4\end{array}$ & $\begin{array}{l}\text { Gestation } \\
>25 w k\end{array}$ \\
\hline Number of patients & 280 & 16 & 5 & 15 \\
Corynebacteria & $234(84)$ & $16(100)$ & $4(80)$ & $10(67)$ \\
Lactobacilli & $229(82)$ & $14(88)$ & $5(100)$ & $13(87)$ \\
Staphylococcus epidermidis & $185(66)$ & $8(50)$ & $2(40)$ & $11(73)$ \\
Micrococci & $103(37)$ & $5(31)$ & 0 & $5(33)$ \\
Faecal streptococci & $96(34)$ & $12(75)$ & $3(60)$ & $3(20)$ \\
Non-haemolytic streptococci & $12(4)$ & 0 & 0 & $2(14)$ \\
Proteus sp. & $17(6)$ & $1(6)$ & 0 & $1(7)$ \\
Escherichia coli & $54(19)$ & $5(31)$ & $1(20)$ & $6(40)$ \\
Mycoplasma hominis & $31(11)$ & $1(6)$ & $1(20)$ & $4(27)$ \\
Staphylococcus aureus & $13(5)$ & $1(6)$ & $1(20)$ & $2(14)$ \\
Bacteroides & $15(5)$ & 0 & 0 & $1(7)$ \\
Anaerobic and microaero- & & & & \\
philic streptococci & $61(22)$ & $3(19)$ & $2(40)$ & $7(47)$ \\
Gram-variable cocco-bacilli & $19(7)$ & $2(12)$ & 0 & $1(7)$ \\
$\beta$-haemolytic streptococci & $25(9)$ & 0 & 0 & $2(14)$ \\
Trichomonas vaginalis & $7(3)$ & 0 & 0 & 0 \\
Torulopsis glabrata & $11(4)$ & $1(6)$ & 0 & $1(7)$ \\
Candida albicans ${ }^{1}$ & $47(17)$ & $4(25)$ & $2(40)$ & $3(20)$ \\
\hline Table II & &
\end{tabular}

Table II Incidence of selected micro-organisms in obstetric high-risk patients

${ }^{1}$ Includes two mixtures of yeasts.

Percentages are given in parentheses.

vaginitis. The isolation of $M$. hominis $(\mathrm{P}<0.05), T$. vaginalis $(\mathrm{P}<0.05)$, and $C$. albicans $(\mathrm{P}<0.02)$ was increased in those patients for whom the obstetrician requested a report. In patients with a past history of vulvovaginitis there was an increased incidence of $T$. vaginalis $(\mathrm{P}<0.05)$.

There were no other associations between the flora isolated and the clinical findings either in the population as a whole or in any of the clinical groups.

\begin{tabular}{|c|c|c|c|}
\hline & $\begin{array}{l}\text { Total } \\
\text { Incidence }\end{array}$ & $\begin{array}{l}\text { Laboratory } \\
\text { Report } \\
\text { Requested }\end{array}$ & $\begin{array}{l}\text { Past } \\
\text { History of } \\
\text { Vulvovagin- } \\
\text { itis }\end{array}$ \\
\hline Number of patients & 280 & 45 & 40 \\
\hline $\begin{array}{l}\text { Corynebacteria } \\
\text { Lactobacilli } \\
\text { Staphylococcus epidermidis } \\
\text { Microcci } \\
\text { Faecal streptococci } \\
\text { Non-haemolytic streptococci } \\
\text { Proteus sp. } \\
\text { Escherichia coli } \\
\text { Mycoplasma hominis } \\
\text { Staphylococcus aureus } \\
\text { Bacteroides } \\
\text { Anaerobic and microaero- } \\
\text { philic streptococci } \\
\text { Gram-variable cocco-bacilli } \\
\text { B-haemolytic streptococci } \\
\text { Trichomonas vaginalis } \\
\text { Torulopsis glabrata } \\
\text { Candida albicans }\end{array}$ & $\begin{array}{c}234(84) \\
229(82) \\
185(66) \\
103(37) \\
96(34) \\
12(4) \\
17(6) \\
54(19) \\
31(11) \\
13(5) \\
15(5)\end{array}$ & $\begin{array}{c}35(77) \\
36(80) \\
27(60) \\
15(33) \\
17(38) \\
0 \\
3(7) \\
13(29) \\
9(20) \\
0 \\
3(7)\end{array}$ & $\begin{array}{c}32(80) \\
33(83) \\
26(65) \\
19(48) \\
11(28) \\
1(3) \\
4(10) \\
11(28) \\
4(10) \\
2(5) \\
2(5)\end{array}$ \\
\hline
\end{tabular}

Table III Incidence of micro-organisms in groups of other high-risk patients

Percentages are given in parentheses. 


\section{Discussion}

This investigation was undertaken to establish broadly the ecology of the lower genital tract in pregnancy as a basis for further studies. We did not seek viruses, Chlamydia, nor T-strain mycoplasmas, but we have observed an incidence of $55.4 \%$ of T-mycoplasmas and $23.1 \%$ of $M$. hominis in pregnant women, using more elaborate cultural methods (de Louvois et al, 1974). Nineteen groups or genera were identified in this study. The organism variously known as Haemophilus vaginalis or Corynebacterium vaginale does not appear in our groups, since we find the taxonomical criteria for its identification uncertain (Lapage, 1961). We have used the term 'Gramvariable coccobacilli' for a group of organisms morphologically resembling $H$. vaginalis or $C$. vaginale, none of which belongs to the genus Haemophilus (Cowan and Steel, 1965), and some of which may be dissociated lactobacilli (Amies and Garabedian, 1963). Otherwise our groups follow the taxonomic criteria of Wilson and Miles (1964) and Cowan and Steel (1965).

We were not surprised by the absence of $\mathrm{Cl}$. welchii, N. gonorrhoeae, L. monocytogenes, Haemophilus species, and Lancefield group A streptococci from the many specimens examined, since these organisms are seldom encountered in our diagnostic practice during the antenatal period. We estimate the incidence of the gonococcus at no more than 1:2500 of our patients (Hurley and Stanley, 1972), an isolation rate that has not increased despite active search in patients who might be suspected, on social or other grounds, to be infected.

The population studied was grouped according to degrees of lower genital tract health or morbidity (Stanley et al, 1975) but only on contrasting healthy patients with those in whom there was any stigma of local morbidity, no matter how slight in degree, did any significant deviation from the standard distribution of microflora emerge. Lactobacilli were less frequently isolated from those with disease of the lower genital tract $(P<0.01)$. This seems consonant with physiological derangement, since the role of lactobacilli in the vagina is thought by some workers (Davis and Pearl, 1938; Wylie and Henderson, 1969) to be the conversion of glycogen to lactic acid, resulting in the acidity of the vagina of the sexually mature woman. The $\mathrm{pH}$ of the vagina alters towards alkalinity in morbid states of the vagina (Karnaky, 1955), but pH was not measured in these studies. Some lactobacilli are allegedly pathogenic (Sharpe $e t$ $a l, 1973)$; our study was not designed to investigate this, and lactobacilli were not speciated. Hence we do not know whether the decline in isolation rate that we report reflects a change in relative distribu- tion within the genus with the decline only of certain species, or an overall decline in incidence.

Although care was taken to record, and to grade, clinical data pertaining to physical examination, no correlation could be shown between recorded signs and symptoms of vulvovaginitis and the isolation of specific microbes, even of those accepted as pathogens. This is at variance with our previous findings with respect to C.albicans (Carroll et al, 1973) and is, we believe, explained by clinical observer variation, as we have previously reported. It is clear that the examining obstetrician is guided by criteria that are not amenable to recording when he comes to assess morbidity of the lower genital tract. We took cognisance of this, stating as a further criterion 'firm opinion of the examining physician' in another study (Stanley et al, 1972), and, in this study, a request for a laboratory report represents a similar expression of clinical opinion.

A laboratory report was requested in 45 cases, and the isolation rates of the two indisputable pathogens, C. albicans $(\mathrm{P}<0.02)$ and $T$. vaginalis $(\mathrm{P}<0.05)$ were increased; so, too, was the isolation rate of $M$. hominis $(\mathrm{P}<0.05)$. This suggests that the rôle of $M$. hominis in the lower genital tract during pregnancy is worth investigating further. The isolation of $T_{0}$ vaginalis also related $(\mathrm{P}<0.05)$ to a past history of vulvovaginitis. These are the only significant corres lations we have demonstrated between morbidits and the isolation rates of specific microbes.

Recently there have been a number of reports on the possible aetiological rôle of Bacteroides species and related organisms in gynaecological and obstetric infections (Neary et al, 1973; Thadepalli et al, 1973; and Craft et al, 1974). The isolation of Bacteroides from $5.4 \%$ of our essentially healthy population, using unsophisticated anaerobic methods, casts doubt on their causative rôle in lower genital tract morbidity, since it is of the same order as that shown by Craft to obtain in women with infections of the genital tract. The study of Thadepalli et al (1973) indicates that Bacteroides may play an aetiological rôle in pelvic abscesses; clearly, the relationship of these and other Gram-negative anaerobes to gynaecological infection merits more extensive study.

The highly significant increase $(P<0.001)$ in the isolation of faecal streptococci from patients over 34 years of age reflects, we believe, a genuine change in ecology contingent on incipient physiological changes that occur in the vagina as women reach the later years of sexual maturity. We think it unlikely that these cocci are transiently present as contaminants from the bowel, or perineum, since the isolation of other faecal microbes did not increase.

The flora of women who booked after the 25th 
week of pregnancy deviated from the normal distribution, and $M$. hominis, E. coli, and anaerobic and microaerophilic streptococci were more frequently isolated from this group. Such women are often feckless, of low social class or low intelligence, or promiscuous; thus, the findings may reflect a casual attitude towards general hygiene.

Because of the difficulty of ascertaining an accurate history of previous contraceptive practices among the patients studied, we are unable to comment whether such have any effect upon the vaginal flora. It is, perhaps, worth remarking that, in our diagnostic practice, the incidence of group B streptococci seems higher in specimens originating from family planning clinics.

There was no correlation between the presence of polymorphonuclear leucocytes and the isolation of specific pathogens, although the presence of pus correlates with lesions of the cervix $(P<0.001)$ (Stanley et al, 1975). There is no evidence that cervicitis is associated with any of the microbes that we have studied.

Our study suggests that, with the possible exception of $M$. hominis, it is unlikely that microbes other than $C$. albicans and $T$. vaginalis play any pathogenic rôle in lower genital tract morbidity during early pregnancy. However, a more detailed examination of the anaerobic organisms present and of the changes in microbial flora as pregnancy progresses may be rewarding.

We thank our colleagues Miss Barbara G. S. Leask, who identified the fungi, and Dr G. King and Dr D. Johnstone, who helped us to program the data.

\section{References}

Amies, C. R. and Garabedian, M. (1963). The bacteriology of human vaginitis. Canad. J. pub. Hlth, 54, 50.

Carroll, C. J., Hurley, Rosalinde, and Stanley, Valerie C. (1973). Criteria for diagnosis of Candida vulvovaginitis in pregnant women. J. Obstet. Gynaec. Brit. Cmwlth, 80, 258-263.

Cowan, S. T. and Steel, K. J. (1965). Manual for the Identification of Medical Bacteria, 1st edition. Cambridge University Press, London.

Craft, I., Ghandi, F., and Hardy, R. (1974). Bacteroides in gynaecological infection. Lancet, 1, 677.

Davis, M. E. and Pearl, S. A. (1938). Biology of the human vagina in pregnancy. Amer. J. Obstet. Gynec., 35, 77-95.

de Louvois, J., Blades, M., Harrison, R. F., Hurley, Rosa- linde, and Stanley, Valerie C. (1974). Frequency of mycoplasma in fertile and infertile couples. Lancet, 1, 1073-1075.

de Louvois, J., Stanley, Valerie C., Hurley, Rosalinde, Jones, J. B., and Foulkes, J. E. B. (1975). Microbial ecology of the female lower genital tract during pregnancy. Postgrad. med. J., 51, 156-160.

Edmunds, P. N. (1959). Haemophilus vaginalis-Its association with puerperal pyrexia and leucorrhoea. J. Obstet. Gynaec. Brit. Emp., 66, 917-926.

Gordon, A. M., Hughes, H. E., and Barr, G. T. D. (1966). Bacterial flora in abnormalities of the female genital tract. J. clin. Path., 19, 429-432.

Hare, M. J. (1973). Serological tests for treponemal disease in pregnancy. J. Obstet. Gynaec. Cmwlth, 80, 515-519.

Hurley, R. and Stanley, V. C. (1972). In Proceedings of an International Symposium on the Diagnosis and Chemotherapy of Urogenital Bacterial Protozoal and Mycotic Infections, edited by F. Gasparri, p. 19. Periti, Florence

Hurley, R., Stanley, V. C., Leask, B. G. S., and de Louvois, J. (1974). Microflora of the vagina during pregnancy. In The Normal Microbial Flora of Man, pp. 155-185. eds. F. A. Skinner and J. G. Carr. Academic Press, London.

Karnaky, K. J. (1955). Electronic studies in obstetrics and gynecology. Obstet. and Gynec., 5, 93-101.

Lapage, S. P. (1961). Haemophilus vaginalis and its role in vaginitis. Acta path. microbiol. scand., 52, 34-54.

Leask, Barbara G. S. and Yarrow, D. (1974). Personal communication.

Neary, M. P., Allen, J., Okubadejo, O. A., and Payne, D. J. H. (1973). Preoperative vaginal bacteria and postoperative infections in gynaecological patients. Lancet, 2, 12911294.

Sharpe, M. E., Hill, L. R., and Lapage, S. P. (1973). Pathogenic lactobacilli. J. med. Microbiol., 6, 281-6.

Slotnick, I. J., Hildebrandt, R. J., and Prystowsky, H. (1963). Microbiology of the female genital tract. IV. Cervical and vaginal flora during pregnancy. Obstet. and Gynec., 21, 312-317.

Slotnick, I. J., Hildebrandt, R. J., Walsh, H., and Prystowsky, H. (1964). Microbiology of the female genital tract. V. Cervical flora in patients with premature rupture of membranes. Obstet. and Gynec., 24, 93-97.

Stanley, Valerie C., Hurley, Rosalinde, and Carroll, C. J. (1972). Distribution and significance of Candida precipitins in sera from pregnant women. J. med. Microbiol., 5, 313-320.

Stanley, Valerie C., Jones, J. B., Hurley, Rosalinde, Foulkes. J. E. B., and de Louvois, J. (1975). Morbidity of the lower genital tract during pregnancy. J. clin. Path., 28, 736740.

Thadepalli, H., Gorbach, S. L., and Keith, L. (1973). Anaerobic infections of the female genital tract: bacteriologic and therapeutic aspects. Amer.J. Obstet. Gynec., 117, 1034-1040.

Wilson, G. S. and Miles, A. A. (1964). Topley and Wilson's Principles of Bacteriology and Immunity, 5th ed. Edward Arnold, London.

Wylie, G. and Henderson, A. (1969). Identity and glycogenfermenting ability of lactobacilli isolated from the vagina of pregnant women. J. med. Microbiol., 21, 363-366. 